This is the peer reviewed version of the following article: Angew. Chem. Int. Ed., 2018, 57, 8326-8329, which has been published in final form at $h$ ttps://onlinelibrary.wiley.com/doi/full/10.1002/anie.201803647. This article may be used for non-commercial purposes in accordance with Wiley Terms and Conditions for Use of Self-Archived Versions.

\title{
A Purely Organic Tricarbanion
}

Denis Höfler, Richard Goddard, Julia B. Lingnau, Nils Nöthling, and Benjamin List*

\begin{abstract}
How many carbanions can an organic molecule accommodate? The formation of purely organic carbanions with multiple charges is challenging as charge stabilization cannot be achieved via metal coordination. So far only quaternary ammonium dicarbanion salts have been reported. ${ }^{[1]} \quad$ Using highly electron-deficient trifluoromethanesulfonyl (triflyl or Tf) groups, the formation of a purely organic tricarbanion could be realized for the first time.
\end{abstract}

Formally, carbanions can be regarded as conjugate bases of $\mathrm{C}-\mathrm{H}$ acids. ${ }^{[2]}$ They play prominent roles as reactive intermediates in a variety of transformations. Classic examples are the Grignard, aldol, Wittig and Knoevenagel reactions. ${ }^{[3]}$ Carbanions can be primarily stabilized through electron-withdrawing groups and metal coordination. Lithiated polycyclic aromatic compounds have been reported with up to four negative charges while lanthanum salts of fullerenes have been observed with formally up to six negative charges. ${ }^{[4]}$ Replacing metals with sterically hindered cations such as organic, quaternary ammonium cations, greatly reduces the degree of ion pairing. ${ }^{[5]}$ As a result, almost "naked" counteranions ${ }^{[6]}$ with associated enhanced nucleophilicity and reactivity are obtained. ${ }^{[6-7]}$ This concept has been leveraged for example in the alkylation of quaternary ammonium enolates. ${ }^{[5,8]}$

In the absence of ion pairing, strong electron withdrawing groups, such as nitrile and triflyl (Tf, trifluoromethanesulfonyl) groups have to be employed to increase the stability of organic carbanionic species. ${ }^{[9]}$ This strategy proved to be successful for the synthesis of several quaternary ammonium dicarbanion salts. ${ }^{[1]}$ However, the formation of higher charged purely organic multi-carbanions has so far, to the best of our knowledge, not been realized. Here we report the synthesis and characterization of the first organic tricarbanion.

Extending our work on strong, allylic C-H acids, ${ }^{[9 b]}$ we recently became attracted to $\mathrm{C}_{3}$ symmetric acid 2 . However, when we reacted triformylmethane ${ }^{[10]}$ with bistriflylmethane,

\section{[*] Prof. Dr. B. List}

Max-Planck Institut für Kohlenforschung

Kaiser-Wilhelm-Platz 1, 45470 Mülheim an der Ruhr (Germany)

E-mail: list@kofo.mpg.de

Supporting information for this article is given via a link at the end of the document.

CCDC1824208 contains the supplementary crystallographic data for this paper. This data can be obtained free of charge from The Cambridge Crystallographic Data Centre. trimethylorthoacetate, and acetic anhydride, followed by subsequent addition of tetraethylammonium bicarbonate, instead of the expected ammonium salt of 2 , we obtained tetraalkylammonium tricarbanion salt 1 (Scheme 1 ). Remarkably, compound $\mathbf{1}$ is not only the first purely organic tricarbanion, but also contains an aldehyde functional group.

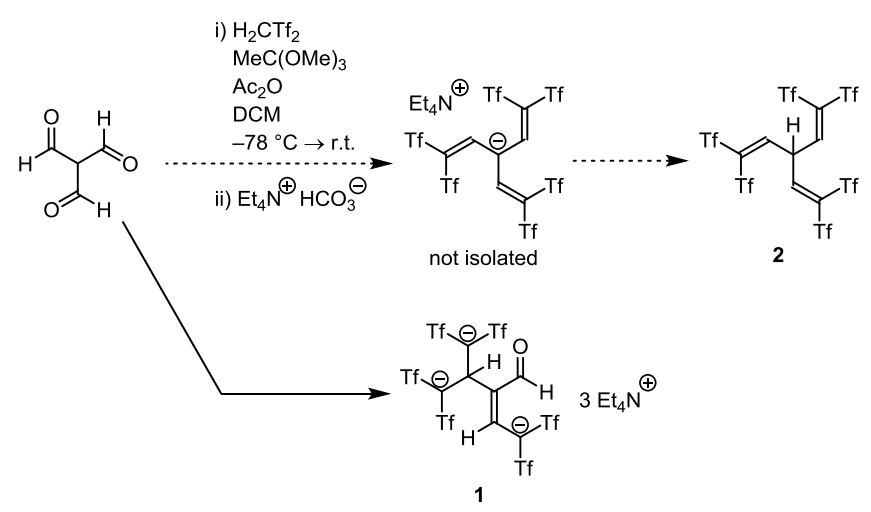

Scheme 1. Route to tricarbanion 1. $\mathrm{Tf}=\mathrm{SO}_{2} \mathrm{CF}_{3}$.

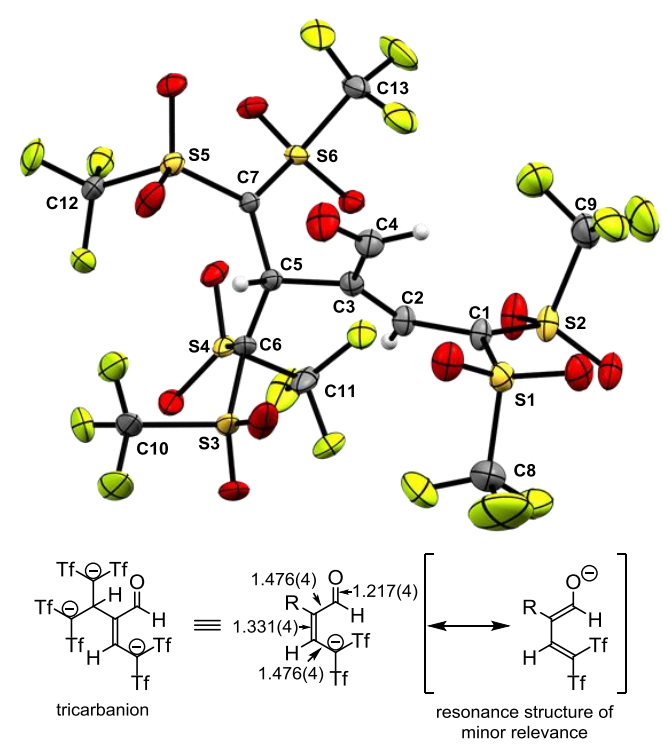

Figure 1. Crystal structure of tricarbanion 1. Selected atoms are labelled. Hydrogen atoms were calculated. For the carbanionic carbons $\mathrm{C} 1, \mathrm{C} 6$, and $\mathrm{C} 7$ the sum of all (surrounding) angles is $358.6^{\circ}, 359.7^{\circ}$, and $359.9^{\circ}$ respectively. Selected bond lengths $(\AA)$ : C4-O1 1.217(4), C4-C3 1.476(4), C3-C2 1.331(4), C2-C1 1.476(4).

The structure of the tricarbanion $\mathbf{1}$ was elucidated by X-ray crystallography (Figure 1). ${ }^{[1]}$ All three carbanionic carbon 
atoms (C1, C6, and $\mathrm{C} 7)$ have trigonal planar geometries. Interestingly, the bond lengths of the $\alpha, \beta$-unsaturated aldehyde moiety are very similar to those of acrolein, ${ }^{[12]}$ ruling out charge delocalization in this group. Rather, these observations suggest that the three negative charges are mainly delocalized in the triflyl moieties.

Remarkably, for all three carbanions in $\mathbf{1}$ the triflyl groups adopt similar conformations despite different crystal environments. For all six $\mathrm{CF}_{3}$ groups the $\mathrm{S}-\mathrm{C}$ bonds lie almost perpendicular to the S,C,S planes of the carbanions (Figure 2). In addition, for each carbanion the $\mathrm{CF}_{3}$ groups of neighboring triflyl groups lie trans to one another.

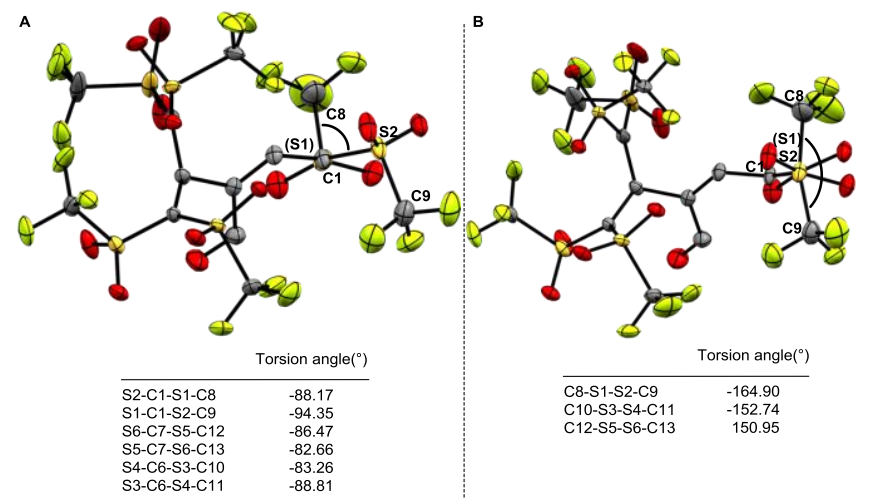

Figure 2. A For all six trifyl groups, the $\mathrm{S}-\mathrm{CF}_{3}$ bond lies almost perpendicular to the mean plane of the adjacent carbanion. $\mathbf{B}$ On each carbanion the $\mathrm{CF}_{3}$ groups point in opposite directions relative to the mean plane of the carbanion. Shown are the respective $\left(\mathrm{F}_{3}\right) \mathrm{C}-\mathrm{S} \cdots \mathrm{S}-\mathrm{C}\left(\mathrm{F}_{3}\right)$ torsion angles.
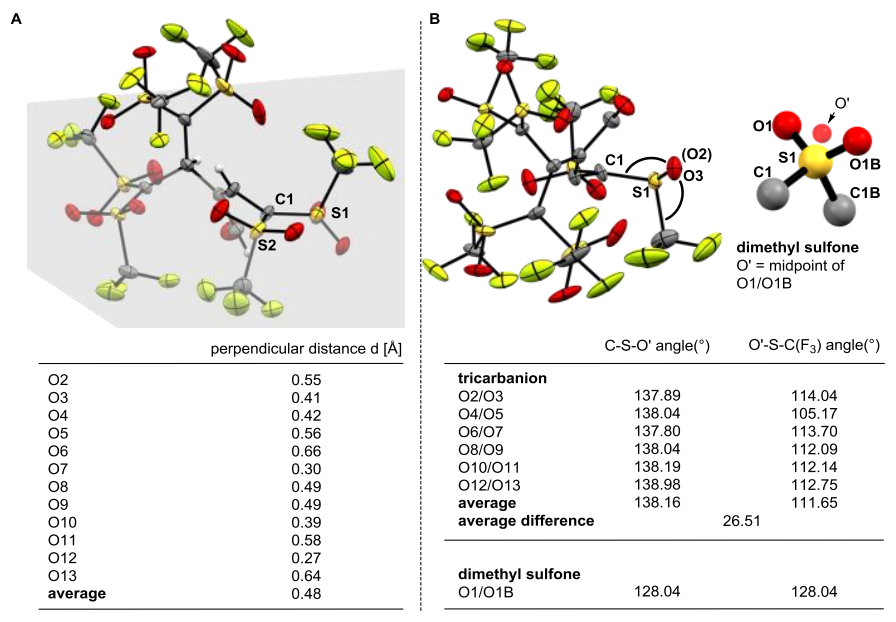

Figure 3. A Displacements of the $O$ atoms in the triflyl groups from the mean plane of the neighboring carbanion. B All six triflyl groups exhibit an increased angle between the carbanion $\mathrm{C}$ atom and the midpoint between the $\mathrm{O}$ atoms of each triflyl group about the sulfur atom, compared with the neutral dimethyl sulfone. ${ }^{[13]}$

Moreover, the oxygen atoms of neighboring triflyl groups lie close to the planes of the respective carbanionic centers (Figure $3 \mathrm{~A}$ ). In each of the six triflyl groups, the $\mathrm{O}$ atoms are bent away from the carbanion $\mathrm{C}$ atom in the direction of the $\mathrm{CF}_{3}$ group. This is most clearly seen by comparing the C-S$O^{\prime}$ angles in each triflyl group, where $O^{\prime}$ is the midpoint of the two $\mathrm{O}$ atoms (Figure $3 \mathrm{~B}$ ). The average difference in the $\mathrm{C}$-S$\mathrm{O}^{\prime}$ angles in 1 is $27^{\circ}$ compared with $0^{\circ}$ in the crystal structure of dimethyl sulfone, where no negative charge is present.
The tendency of both oxygen atoms to lie in the plane of the carbanion may improve the negative charge delocalization between the carbanionic center and its neighboring four triflyl oxygen atoms.

The fact that the aldehyde is stable against further nucleophilic attack indicates anionic charge stabilization amongst the triflyl groups. Theoretical calculations on the model species dimethyl sulfone, trifluoromethyl(methyl)sulfone and the carbanion 1,1-ditriflylethan-1-ide (see Supporting Information) reproduce the tendency of the triflyl $O$ atoms to adopt a position close to the plane of the carbanion. Further, a statistical evaluation of ditriflylcarbanion crystal structures from the Cambridge Structure Database also supports this observation (see Supporting Information).

The notion of a build-up of negative charge on the triflyl oxygen atoms is also supported by the fact that several of the $\mathrm{O}$ atoms exhibit short $\mathrm{O} \cdots \mathrm{H}-\mathrm{C}(\mathrm{N})$ hydrogen bonding interactions with the $\alpha$-hydrogens of the tetraethyl ammonium cation (Figure 4). The shortest $\mathrm{O} \cdots \mathrm{C}$ distance is $3.219(4) \AA$ and is comparable to the $\mathrm{O} \cdots \mathrm{H}-\mathrm{C}(\mathrm{N})$ distances observed in the crystal structures of the tetrabutylammonium salts of malonic acid dialkyl esters. ${ }^{[6]}$ This is further supported by a previously reported charge density study of the $\mathrm{SO}_{4}{ }^{2-}$ anion in which the oxygen atoms carry considerable negative charge. ${ }^{[14]}$

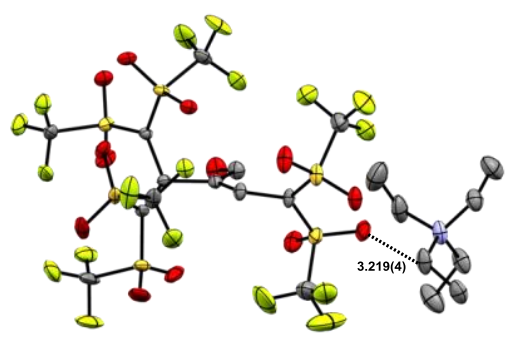

Figure 4. Crystal structure of the tricarbanion showing the interaction of the molecules with one tetraethyl ammonium cation. A $(\mathrm{N}) \mathrm{C}(-\mathrm{H}) \cdots \mathrm{O}$ hydrogen bonding interaction with a distance of 3.219(4) A between the sulfonyl oxygen of the tricarbanion and the $\alpha$-carbon atom of the cation is observed.

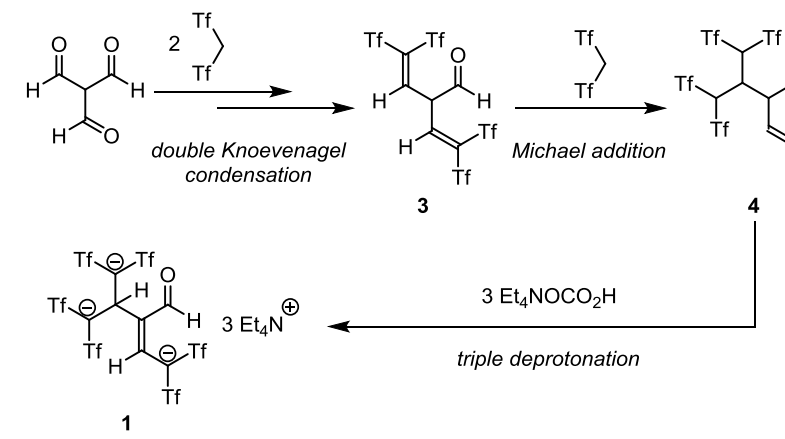

Scheme 2. Plausible pathway to tricarbanion 1.

At the moment, we have no evidence on how the tricarbanion is formed under these reaction conditions. However, a likely pathway can be proposed (Scheme 2). Accordingly, triformylmethane could react with two equivalents of bistriflylmethane to give aldehyde $\mathbf{3}$ in a Knoevenagel condensation. ${ }^{[15]}$ This is followed by a Michael 
addition of bistriflylmethane, rather than a third Knoevenagel condensation, to give the desired tricarbanion after deprotonation. Studies to clarify this are currently underway.

In conclusion, although tetraalkylammonium ions are only weakly coordinating cations and as such provide limited electrostatic stabilization, the formation of a purely organic tricarbanion salt has been observed for the first time. Our results showcase the exceptional anion stabilizing ability of triflyl groups which we consider essential for the formation of stable highly charged anionic species, opening the possibility of the formation of organic polycarbanions.

\section{Acknowledgements}

Generous support by the Max-Planck-Society, the Deutsche Forschungsgemeinschaft (Leibniz Award to B.L. and Cluster of Excellence RESOLV, EXC 1069), and the European Research Council (Advanced Grant " $\mathrm{C}-\mathrm{H}$ Acids for Organic Synthesis, CHAOS") is gratefully acknowledged. R.G. thanks J. Breidung for helpful discussions. We thank the members of our analytical departments for their excellent service.

Keywords: tetraalkylammonium cation - purely organic tricarbanion $\bullet$ highly charged anion $\bullet$ triflyl stabilization

[1] a) A. Hasegawa, T. Ishikawa, K. Ishihara, H. Yamamoto, Bull. Chem. Soc. Jpn. 2005, 78, 1401-1410; b) J. Lu, T. H. Le, D. A. K. Traore, M. Wilce, A. M. Bond, L. L. Martin, J. Org. Chem. 2012, 77, 10568-10574; c) T. Mitsuhashi, M. Goto, K. Honda, Y. Maruyama, T. Inabe, T. Sugawara, T. Watanabe, Bull. Chem. Soc. Jpn. 1988, 61, 261-269.

[2] D. J. Cram, Fundamentals of carbanion chemistry, Vol. 4, Elsevier, 2012.

[3] B. List, Acc. Chem. Res. 2004, 37, 548-557.

[4] a) A. S. Filatov, A. V. Zabula, S. N. Spisak, A. Y. Rogachev, M. A. Petrukhina, Angew. Chem. Int. Ed. 2014, 53, 140-145; b) A. V. Zabula, A. S. Filatov, S. N. Spisak, A. Y. Rogachev, M. A. Petrukhina, Science 2011, 333, 1008-1011; c) M. Yamada, et al., J. Am. Chem. Soc. 2015
137, 232-238; d) L. Feng, et al., J. Am. Chem. Soc. 2006, 128, 59905991.

[5] R. Noyori, I. Nishida, J. Sakata, J. Am. Chem. Soc. 1983, 105, 15981608.

[6] M. T. Reetz, S. Hütte, R. Goddard, J. Am. Chem. Soc. 1993, 115, 9339 9340 .

[7] a) M. B. Smith, J. March, in March's Advanced Organic Chemistry, 3rd ed., John Wiley \& Sons, Inc., 2006, pp. 320-322; b) C. M. Starks, J. Am. Chem. Soc. 1971, 93, 195-199.

[8] a) I. Kuwajima, E. Nakamura, J. Am. Chem. Soc. 1975, 97, 3257-3258; b) I. Kuwajima, E. Nakamura, Acc. Chem. Res. 1985, 18, 181-187.

[9] a) C. Hansch, A. Leo, R. W. Taft, Chem. Rev. 1991, 91, 165-195; b) D. Höfler, M. van Gemmeren, P. Wedemann, K. Kaupmees, I. Leito, M. Leutzsch, J. B. Lingnau, B. List, Angew. Chem. Int. Ed. 2017, 56, 1411 1415; c) L. Turowsky, K. Seppelt, Inorg. Chem. 1988, 27, 2135-2137.

[10] Z. Arnold, M. Budesinsky, J. Org. Chem. 1988, 53, 5352-5353.

[11] Please see reference [16] for crystal data.

[12] a) K. Kuchitsu, T. Fukuyama, Y. Morino, J. Mol. Struct. 1968, 1, 463479; b) T. S. Thakur, M. T. Kirchner, D. Bläser, R. Boese, G. R. Desiraju, Phys. Chem. Chem. Phys. 2011, 13, 14076-14091.

[13] S. P. Thomas, M. W. Shi, G. A. Koutsantonis, D. Jayatilaka, A. J. Edwards, M. A. Spackman, Angew. Chem. Int. Ed. 2017, 56, 84688472.

[14] M. S. Schmøkel, S. Cenedese, J. Overgaard, M. R. V. Jørgensen, Y.-S. Chen, C. Gatti, D. Stalke, B. B. Iversen, Inorg. Chem. 2012, 51, 86078616.

[15] a) H. Yanai, S. Egawa, T. Taguchi, Tetrahedron Lett. 2013, 54, 2160 2163; b) H. Yanai, H. Ogura, H. Fukaya, A. Kotani, F. Kusu, T. Taguchi, Chemistry 2011, 17, 11747-11751.

[16] The crystal structure of $1: \mathrm{C}_{38} \mathrm{H}_{65} \mathrm{Cl}_{2} \mathrm{~F}_{18} \mathrm{~N}_{3} \mathrm{O}_{13} \mathrm{~S}_{6}, \mathrm{Mr}=1377.19$ g.mol ${ }^{-1}$, colourless prism, monoclinic, $P 2_{1} / \mathrm{c}$ (no. 14), $a=11.372(2) \AA, b=$ 45.769(8) $\AA, c=12.482(2) \AA, \beta=115.053(3)^{\circ}, V=5885.3(17) \AA^{3}, T=$ $100(2) \mathrm{K}, Z=4, d_{\text {calcd }}=1.554 \mathrm{Mgm}^{-3}$, Mo-Ka radiation, $\lambda=0.71073 \AA$. Further details of the crystal structure analysis are given in the Supporting Information. CCDC-1824208. 